\title{
FRACTURE RESISTANCE AND FAILURE MODE OF COMPOSITE ENDOCROWNS FOR MAXILLARY PREMOLARS: NEW RESTORATIVE APPROACHES
}

\author{
Yasser A. Abed* and Maha E. Elkorashy**
}

\begin{abstract}
Objective: To investigate fracture resistance and failure mode of maxillary premolars restored with resin composite endocrowns prepared using different restorative approaches in comparison to ceramic endocrowns.

Methods: Fifty sound human maxillary premolars were used in the current study. Teeth were randomly divided into five groups according to restorative approach used in fabrication of endocrowns; group I: resin composite material, group II: composite modeled with resin adhesive, group III: composite modeled with flowable composite, group IV: ceramic material and group V: intact premolars (Control group).Teeth assigned for group I, II, III and IV were endodontically treated and prepared for endocrowns with internal depth $4 \mathrm{~mm}$ and cervical margin $2 \mathrm{~mm}$. Endocrowns were fabricated and tested for fracture resistance using universal testing machine. Failure mode was assessed under a stereomicroscope. Data were tabulated and statistically analyzed.
\end{abstract}

Results: Fracture resistance results showed no significant difference between control group

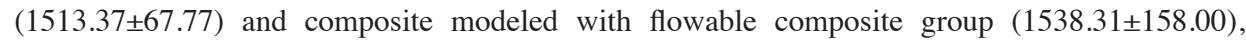
resin composite group $(1434.7 \pm 117.60)$ and composite modeled with resin adhesive group (1396.57 \pm 83.03$)$. Ceramic group $(707.79 \pm 127.05)$ recorded the lowest mean values. Regarding failure mode, ceramic group recorded mainly irreparable failures while other experimental groups recorded reparable ones.

Conclusion: Resin composite endocrowns is better choice compared to ceramic ones in restoration of endodontically treated premolars. Modeling of resin composite using flowable composite and resin adhesive is considered a promising approach in restoration of endodontically treated premolars with more favorable fracture behavior than ceramic materials.

KEY WORDS: Fracture resistance, Failure mode, Composite endocrowns, Ceramic endocrowns.

* Associate Professor of Operative Dentistry, Faculty of Dentistry, October 6 University, Egypt.

** Associate Professor of Operative Dentistry, Faculty of Dentistry, Fayoum University, Egypt. 


\section{INTRODUCTION}

Restoration of endodontically treated teeth is still challenging in terms of durability. Endodontically treated teeth are weak and susceptible to fracture due to mechanical loss of dental tissues as a consequence of dental caries, access cavity and canal preparation during endodontic treatment in addition to loss of tooth vitality ${ }^{(1,2)}$.

Different restorative approaches have been applied in restoration of endodontically treated teeth as direct resin composite restorations, ceramic inlays, onlays as well as post-core and crown. Application of post and core followed by full crown restoration was one of the most commonly used treatments for years ${ }^{(3,4)}$. Although post is used as a retentive feature for coronal restoration, it presents a great risk of failure as it can result in canal perforation, root fracture or total loss of the tooth ${ }^{(4,5)}$.

Endocrowns were firstly described as adhesive endodontic total porcelain crowns fixed to endodontically treated posterior teeth ${ }^{(6)}$. They require minimally invasive preparations with two-fold retention mechanism; macro-mechanical retention obtained from internal walls of the pulp chamber and cavity margins and micromechanical retention provided by the use of adhesive resin cements ${ }^{(7)}$. It was suggested that endocrowns result in homogenous transmission of occlusal stresses in posterior teeth than intra-radicular posts thus, providing better clinical performance and durability ${ }^{(3)}$.

Ceramics have been the material of choice for fabrication of endocrowns for many years ${ }^{(1,7,8,9)}$. Ceramic materials are characterized by their high stiffness and minimal elasticity. These properties could result in catastrophic failures during clinical service ${ }^{(10)}$. Use of restorative materials with mechanical properties matching to that of the tooth structure can offer better clinical performance ${ }^{(11)}$.

Resin composites met the increasing demand for esthetic restorations for anterior and posterior teeth in both direct and indirect approaches ${ }^{(12)}$. The low elastic modulus of polymeric materials resulted in wide spread use of resin composite restorations in posterior area. This is because of their stress absorbing properties which are clinically recommended in such areas ${ }^{(2,13,14)}$. It is preferred to use composite materials with modulus of elasticity close to that of dentin as a valuable alternative to ceramic endocrowns ${ }^{(9)}$. Another advantage of using resin composite is that it can be easily repaired inside the oral cavity ${ }^{(2)}$.

Fracture pattern of the restorative system is one of the most important criteria that determine tooth durability. It is greatly influenced by the materials' properties. Repairable fractures are always preferrable than aggressive or irreparable ones. Fractures involving the root are result in either tooth loss and extraction or they might require invasive surgical procedure to be properly restored which are usually complex, time consuming and expensive ${ }^{(11)}$.

Recently, a new approach has been described which is the use of less viscous resin adhesive as a modeler liquid. Resin adhesive is applied as an intermediate layer between resin composite increments during fabrication of resin composite endocrowns $^{(15)}$. A previous study found that the cohesive strength of resin composite was significantly improved when the composite was modeled using low viscosity adhesive resin. This leads to better stress distribution with less aggressive failure patterns ${ }^{(16)}$.

Flowable composites are low elastic modulus composites due to their low filler loading, $60-70 \%$ by weight and $46-70 \%$ by volume and hence they can act as flexible intermediate layer ${ }^{(17,18)}$. Based on the concept of modeling of resin composite using low elastic modulus materials, a new approach has been applied in the current study where modeling was done using flowable resin composite material during fabrication of resin composite endocrowns.

Maxillary premolars are commonly known by their unfavorable fracture resistance due to their anatomy, crown size and crown/root ratio. They are more susceptible to cusp fractures under occlusal loads ${ }^{(11)}$. Premolars are subjected to lateral 
(non-axial) forces during mastication more likely than molars ${ }^{(19)}$. A previous study reported $31 \%$ failure incidence of endocrowns used for premolars and attributed this to the low surface area available for bonding ${ }^{(8)}$. On contrary, another study reported that endocrowns are reliable approach for restoration of premolars even with extensive coronal tissue loss ${ }^{(20)}$.

Therefore, the current study was conducted to assess fracture resistance and failure mode of maxillary premolars restored using resin composite endocrowns prepared using different restorative approaches in comparison to ceramic endocrowns.

\section{MATERIALS AND METHODS}

\section{Teeth Selection and Grouping}

A total of fifty sound freshly extracted human maxillary premolars were used in the current study. The study was approved by the research ethics committee of October 6 university, Giza, Egypt (RECO6U) with approval number RECO6U/ 6-2021. Premolars were washed under running water, scaled to remove any plaque, calculus or adhering soft tissues and then they were stored in saline at $4^{\circ} \mathrm{C}$ for not more than one month. Teeth were selected with average dimensions of $8 \pm 0.5 \mathrm{~mm}$ bucco-lingual width and $7 \pm 0.5 \mathrm{~mm}$ mesio-distal width. All measurements were taken at the level of the cementoenamel junction using digital caliper (Mitutoyo, Digimatic Caliper, Mitutoyo Corporation, Tokyo, Japan). Inclusion criteria for the teeth were absence of cracks, fractures and caries whether in teeth crowns or roots.

Teeth were randomly divided into five groups ( $\mathrm{n}=10)$ according to restorative approach used in fabrication of endocrowns as follow: group I: Resin composite material, group II: Composite modeled with resin adhesive, group III: Composite modeled with flowable composite, group IV: Ceramic material and group V: Intact premolars (Control group).

\section{Endodontic Treatment}

Premolars assigned to groups I, II, III and IV were endodontically treated. Access cavity was prepared with round diamond bur (öko Dent, Germany) at high speed and extirpation was done to remove any remnants of pulp tissue. The working length of each tooth was determined using \# 15 K File (Mani, Utsunomiya, Tochigi, Japan). Each premolar was instrumented to an apical size of 35 using K File. Gates glidden drill was used for preparation of the coronal two thirds (Mani, Utsunomiya, Tochigi, JAPAN). During filing, each canal was irrigated with saline, dried using absorbent paper points (Diadent group, Korea), obturated with gutta-percha (Meta Biomed Dental, Korea) and sealed with an epoxy resin-based sealer (ADSEAL; Meta Biomed Dental, Korea). Root canals were obturated using cold lateral condensation technique.

\section{Teeth Preparation for Endocrowns}

Rubber base impression was taken for each premolar before any preparation in order to be used as a template during fabrication of the endocrown. After impression taking, occlusal reduction was done $2 \mathrm{~mm}$ above cemento-enamel junction, measured from proximal side. Preparation was done by making orientation grooves, then coarse grit diamond wheels were used for completion of occlusal preparation (öko Dent, Germany). The diamond wheels were used parallel to the occlusal plane to achieve smooth flat cavity margins. Internal cavities were prepared inside the pulp chamber by removing the undercuts of the pulp chamber and aligning its axial walls with an internal taper of $8^{\circ}-10^{\circ}$ using diamond tapered bur with rounded end (öko Dent, Germany) held perpendicular to the pulpal floor. The axial walls were prepared from the pulpal side to provide cavity margins with standardized thickness $(2 \pm 0.2$ $\mathrm{mm}$ ) using a digital caliper (Mitutoyo, Digimatic Caliper, Mitutoyo Corporation, Tokyo, Japan) with an accuracy of $\pm 0.02 \mathrm{~mm}$. Internal cavities prepared with depth $4 \mathrm{~mm}$ which were measured using a periodontal graded probe. All specimens were prepared by the same operator to ensure standardization. 
TABLE (1): Materials used in the study

\begin{tabular}{|c|c|c|c|c|}
\hline \multicolumn{2}{|c|}{ Brand name and description } & Composition & Lot no. & Manufacturer \\
\hline \multicolumn{2}{|c|}{$\begin{array}{l}\text { Optibond All in One } \\
\text { (Single component light cure } \\
\text { self-etch adhesive) }\end{array}$} & $\begin{array}{l}\text { Glycerol phosphate dimethyacrylate (GPDM), } \\
\text { mono and difunctional methacrylate monomers, } \\
\text { water, acetone and ethanol, camphorquinone, } \\
\text { three nano-sized fillers ( } 7 \% \text { ), sodium hexafluo- } \\
\text { rosilicate and ylterbium floride }\end{array}$ & 7528935 & \multirow{3}{*}{$\begin{array}{l}\text { Kerr Corporation, } \\
\text { Orange, USA } \\
\text { www.kerrdental.com }\end{array}$} \\
\hline \multicolumn{2}{|c|}{$\begin{array}{l}\text { Herculite XRV Ultra } \\
\text { (Nanohybrid Composite) }\end{array}$} & $\begin{array}{l}\text { Bis-GMA, TEGDMA, } 78 \mathrm{wt} \% \text { Fillers barium } \\
\text { glass filler }(0.4 \mu \mathrm{m}) \text { and silicon dioxide }(0.02- \\
0.05 \mu \mathrm{m})\end{array}$ & 7515720 & \\
\hline \multicolumn{2}{|c|}{$\begin{array}{l}\text { Herculite XRV Ultra Flow } \\
\text { (Nanohybrid Flowable } \\
\text { Composite) }\end{array}$} & $\begin{array}{l}\text { Ethoxylated Bisphenol A-dimethacrylate (10- } \\
30 \%) \text { - 2,2-ethylenedioxydiethyl dimethacrylate } \\
(1-10 \%) \text { - 3-Methacryloxypropyltrimethoxysi- } \\
\text { lane (1-5\%) - bisphenol A-glycidyl methacrylate } \\
\text { (Bis-GMA) }(1-5 \%)\end{array}$ & 7429520 & \\
\hline \multirow{4}{*}{$\begin{array}{l}\text { DUO-LINK } \\
\text { UNIVERSAL } \\
\text { (Adhesive } \\
\text { Cementation } \\
\text { System) }\end{array}$} & $\begin{array}{l}\text { All Bond } \\
\text { Universal }\end{array}$ & 10-MDP, Bis-GMA, HEMA, ethanol - initiator & 200000591 & \multirow{5}{*}{$\begin{array}{l}\text { Bisco, INC, } \\
\text { Schaumburg, USA } \\
\text { www.bisco.com }\end{array}$} \\
\hline & $\begin{array}{l}\text { Resin luting } \\
\text { cement }\end{array}$ & Bis-GMA ,TEGDMA, UDMA, fiber glass & 2000005821 & \\
\hline & $\begin{array}{l}\text { Porcelain } \\
\text { primer }\end{array}$ & Pre-hydrolyzed silane coupling agent & 2000005687 & \\
\hline & Z Prime Plus & $\begin{array}{l}\text { MDP phosphate monomer and BPDM carboxyl- } \\
\text { ate monomer }\end{array}$ & 2000005878 & \\
\hline \multicolumn{2}{|c|}{$\begin{array}{l}\text { Porcelain etchant gel } \\
\text { (Hydrofluoric acid) }\end{array}$} & $9.5 \%$ buffered Hydrofluoric acid & 2000007850 & \\
\hline \multicolumn{2}{|c|}{$\begin{array}{c}\text { Meta Etchant } \\
\text { (Phosphoric acid) }\end{array}$} & $37 \%$ phosphoric acid etchant gel & 2010061 & $\begin{array}{l}\text { Meta Biomed Dental, } \\
\text { Korea } \\
\text { www.meta-biomed.com }\end{array}$ \\
\hline \multicolumn{2}{|c|}{ IPS e.max press } & Lithium disilicate glass ceramic & X00771 & $\begin{array}{c}\text { Ivoclar Vivadent } \\
\text { Schaan, Liechtenstein } \\
\text { www.ivoclarvivadent.com }\end{array}$ \\
\hline
\end{tabular}

\section{Molding of Teeth}

A customized mold was prepared for each premolar with length $2 \mathrm{~cm}$ and internal diameter 1.5 $\mathrm{cm}$. Self-cured acrylic resin (Acrostone, Egypt) was mixed with standardized proportions and applied inside the molds. Each premolar was vertically applied and centralized in the acrylic resin with their long axis perpendicular to the base of the mold. The roots were embedded in acrylic resin, while it was in the dough stage, up to $2 \mathrm{~mm}$ below the cementoenamel junction (CEJ) to simulate the bone level and left until complete setting of the acrylic resin. 


\section{Fabrication of Endocrowns}

Materials used in this study are illustrated in table 1. Regarding group I, each specimen was restored using nanohybrid resin composite (Herculite XRV ultra, Kerr Corporation, Orange USA). Separating fluid (Ivoclar Vivadent Schaan, Liechtenstein) was applied to the cavity walls and margins before composite application to facilitate removal of endocrowns after fabrication. Resin composite was applied in increments, $2 \mathrm{~mm}$ in thickness. The previously prepared rubber base impression templates were used in the final stages of fabrication of composite endocrowns to simulate anatomy of the prepared premolars. Each layer was cured for $20 \mathrm{sec}$ using light curing unit (Elipar ${ }^{\mathrm{TM}}$ S10 LED curing light, 3M ESPE) with light intensity 1200 $\mathrm{mWcm}^{2}$. The light intensity was checked regularly after fabrication of endocrowns for each group using radiometer (C10 Light Meter, Premium plus, China). The endocrowns were removed after initial curing, then additional polymerization was applied for $20 \mathrm{sec}$ using a specialized oven (bre.Lux PowerUnit 2, Led full range system, bredent, Gmbh \& Co. kG, Senden. Cermany).

Specimens assigned for group II were prepared in the same manner as mentioned in group I except for modeling using resin adhesive. After application of each increment of resin composite, a layer of adhesive (Obtibond, all in one, Kerr Corporation, Orange USA) was applied using microbrush and then both composite increment and adhesive layer were cured together.

In group III, each composite increment was modeled with a continuous uniform layer of nanohybrid flowable composite (Herculite XRV Ultra flow, Kerr Corporation, Orange, USA). Each layer was cured separately for $20 \mathrm{sec}$ before application of the next increment till completion of the restoration.

Endocrowns assigned for group IV were fabricated indirectly using lithium disilicate ceramic (IPS e.max, Ivoclar Vivadent, Schaan, Liechten- stein). The specimens were scanned with a CAD/ CAM scanner. The wax sprues were attached to each endocrown before investing. The preheating cycle was accomplished at $850^{\circ} \mathrm{C}$ for one hour. The molds were placed in a furnace and pressed with IPS e.max press ingot material at $915^{\circ} \mathrm{C}$ for $20 \mathrm{~min}$ using the Ivoclar P 700 Press (Ivoclar vivadent, Vadus, liechtenstein). The fabricated endocrowns were separated and glazed.

\section{Cementation of Endocrowns}

The prepared enamel surfaces of premolars were etched with 37\% phosphoric acid gel (Meta Etchant, Meta Biomed Dental, korea) for $20 \mathrm{sec}$, rinsed for $20 \mathrm{sec}$ and then air dried. Two separate coats of adhesive (All-Bond Universal, DUOLINK UNIVERSAL, Bisco, schaumburg. USA) were applied to the preparation using a microbrush in a scrubbing motion for $15 \mathrm{sec}$ per coat, excess solvent was evaporated by air drying for $5 \mathrm{sec}$ then light cured for $10 \mathrm{sec}$ (3M ESPE, Elipar) according to manufacturer's recommendation.

Before cementation of composite endocrowns, their inner surfaces were sandblasted using $50 \mu \mathrm{m}$ aluminum oxide particles for $10 \mathrm{sec}$ with a pressure 2.5 bars from a distance $10 \mathrm{~mm}$. The surfaces were decontaminated in an ultrasonic cleaner (Model WUC-D06H, Wisd, Korea) with ethanol solution then rinsed and air dried. One coat of primer (ZPRIME Plus, DUO-LINK UNIVERSAL, Bisco, Schaumburg, USA) was applied to the inner surfaces of the endocrowns and air dried for $5 \mathrm{sec}$ according to the manufacturers' instructions.

Composite endocrowns were cemented with dual-cure resin cement (DUO-LINK UNIVERSAL, Bisco, Schaumburg, USA). The cement was applied onto the inner surfaces of endocrowns, then endocrowns were seated in place with light finger pressure. Excess luting cement was removed using scalpel after $15 \mathrm{sec}$ of application to avoid disruption of restoration marginal integrity. The resin cement was light activated at buccal, lingual, mesial and distal directions for $40 \mathrm{sec}$ each. 
For cementation of ceramic endocrowns, inner surfaces of endocrowns were sandblasted using $50 \mu \mathrm{m}$ aluminum oxide particles for $10 \mathrm{sec}$ with a pressure 2.5 bars from a distance $10 \mathrm{~mm}$. After sandblasting, inner surfaces were etched using $9.5 \%$ hydrofluoric acid (Bisco, Schaumburg, USA) for 20 $\mathrm{sec}$, rinsed for $20 \mathrm{sec}$ and then air dried. One coat of porcelain primer (DUO-LINK UNIVERSAL, Bisco, Schaumburg, USA) was applied and left for $30 \mathrm{sec}$, air dried for $5 \mathrm{sec}$ then cement was applied in the same manner as mentioned before. All of the specimens were stored in distilled water at room temperature for 24 hours before testing.

\section{Fracture Resistance Testing}

The fracture resistance test was carried out using universal testing machine (Instron 3345- England) for all experimental groups. A stainless-steel ball $(6 \mathrm{~mm}$ in diameter) was applied perpendicular to the occlusal plane and centered on the occlusal surface of each restoration. Compressive force was applied through the ball with a cross head speed of $1 \mathrm{~mm} /$ min until fracture occurred. The maximum load up to fracture was recorded in Newtons $(\mathrm{N})$.

\section{Failure Mode Assessment}

Fractured patterns of the specimens were examined under a stereomicroscope (M A 100 Nikon. Japan) at magnification $40 \mathrm{X}$ to determine failure mode. Failure mode was classified as follow: Type I fractures involving a small portion of the coronal tooth structure or the restoration; Type II fractures involving a large portion of the coronal tooth structure and/or cohesive failure of the restoration; Type III fractures involving the tooth structure, cohesive and/or adhesive failure of the restoration, with root involvement above the level of the bone crest; Type IV severe crown and root fracture beyond the level of the bone crest.

\section{Statistical Analysis}

Numerical data was represented as mean and standard deviation (SD) values. The data was normally distributed, as assessed by ShapiroWilk's test of normality $(\mathrm{p}>0.05)$ and there was homogeneity of variances $(p>0.05)$ as assessed by Levene's test ( $p>0.05)$. One-way ANOVA followed by Tukey's post hoc test were used to analyze intergroup comparisons for mean fracture resistance values. Failure mode was presented as frequency and percentage values and was analyzed using Fisher's exact test followed by pairwise comparisons utilizing multiple z-tests with Bonferroni correction. The significance level was set at $\mathrm{p}<0.05$ within all tests. Statistical analysis was done with R statistical analysis software version 4.1.1 for Windows*.

\section{RESULTS}

Descriptive statistics and intergroup comparison for mean fracture resistance values $(\mathrm{N})$ were presented in table (2). Results showed that there was a significant difference between fracture resistance values in different groups $(\mathrm{p}<0.001)$. The highest values were found in Composite modeled with flowable composite $(1538.31 \pm 158.00)$, followed by Control group $(1513.37 \pm 67.77)$, then Resin composite group $(1434.70 \pm 117.60)$ and Composite modeled with resin adhesive (1396.57 \pm 83.03$)$ with no significant difference between them. The significantly lowest mean value was recorded with the Ceramic group (707.79 \pm 127.05$)$.

Distribution of failure modes in different experimental groups was presented in figure (1). Results showed that there was a significant difference between different groups $(\mathrm{p}<0.001)$. Type (III) failure was recorded by $50 \%$ of Resin composite group specimens, $50 \%$ of Composite modeled with resin adhesive group specimens and $40 \%$ of Composite modeled with flowable composite group specimens. A total of $70 \%$ of Ceramic group specimens

* R Core Team (2021). R: A language and environment for statistical computing. R Foundation for Statistical Computing, Vienna, Austria. URL https://www.Rproject.org/. 
recorded type (IV) failure, while $90 \%$ of control group specimens recorded type (I) failure. Post hoc pairwise comparisons showed that the control group have a significantly higher percentage of specimens recorded type (I) failure than other experimental groups $(\mathrm{p}<0.001)$. In addition, Ceramic group showed a significantly higher percentage of type (IV) failure than the control group $(\mathrm{p}<0.001)$.

TABLE (2): Descriptive statistics and intergroup comparison for fracture resistance (N)

\begin{tabular}{|c|c|c|c|c|c|c|}
\hline \multirow{2}{*}{ Treatment } & \multirow{2}{*}{ Mean } & \multirow{2}{*}{ SD } & \multicolumn{2}{|c|}{$95 \% \mathrm{CI}$} & \multirow{2}{*}{ Median } & \multirow{2}{*}{ IQR } \\
\hline & & & Lower & Upper & & \\
\hline Resin composite & $1434.70^{\mathrm{A}}$ & 117.60 & 1353.21 & 1516.19 & 1429.96 & 205.19 \\
\hline Composite modeled with resin adhesive & $1396.57^{\mathrm{A}}$ & 83.03 & 1339.04 & 1454.11 & 1392.41 & 89.00 \\
\hline $\begin{array}{l}\text { Composite modeled with flowable } \\
\text { composite }\end{array}$ & $1538.31^{\mathrm{A}}$ & 158.00 & 1428.83 & 1647.79 & 1534.75 & 284.74 \\
\hline Ceramic & $707.79^{\mathrm{B}}$ & 127.05 & 619.75 & 795.84 & 713.86 & 197.00 \\
\hline Control & $1513.37^{\mathrm{A}}$ & 67.77 & 1466.40 & 1560.33 & 1512.23 & 105.20 \\
\hline
\end{tabular}

95\%CI= 95\% confidence interval for the mean; $S D=$ standard deviation; IQR=interquartile range. Different superscript letters indicate a statistically significant difference; *significant $(p<0.05)$

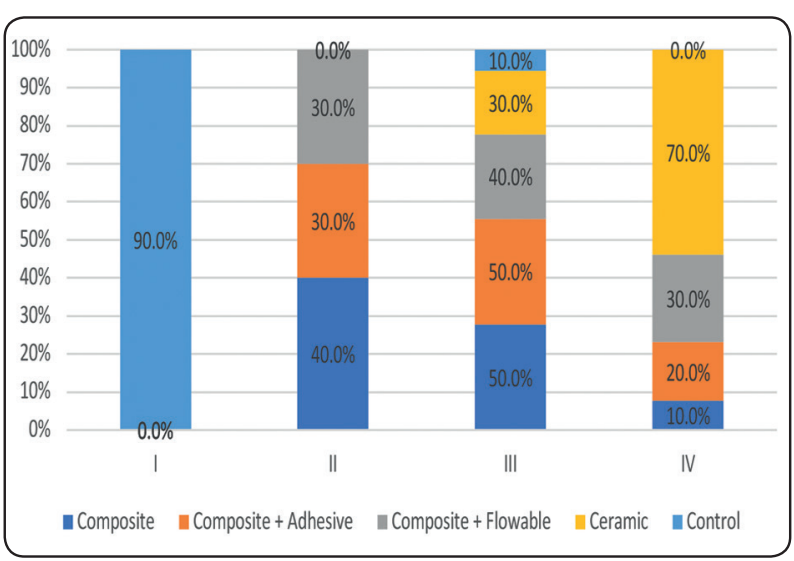

Fig. (1) Bar chart showing failure modes in different experimental groups

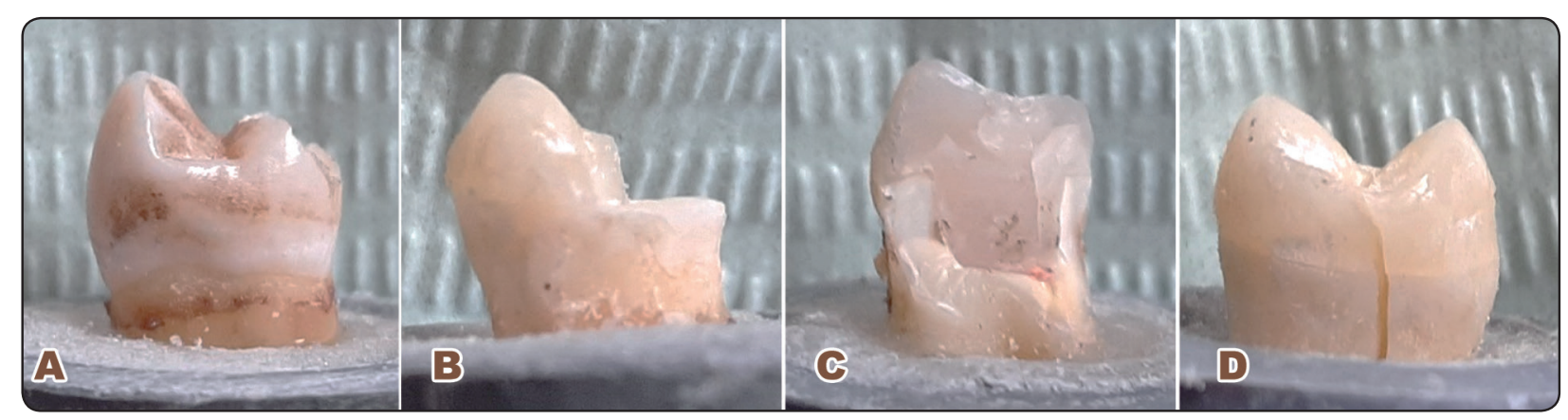

Fig. (2): An image showing different fracture patterns; A) Type I; B) Type II, C) Type III and D) Type IV 


\section{DISCUSSION}

Premolars with extensive loss of coronal tooth structure have been traditionally restored by cast metal or fiberglass reinforced composite post and crown ${ }^{(21)}$. Among different treatments required for root canal treated teeth, endocrowns are considered time saving, less expensive and of easy procedure ${ }^{(22)}$. In addition, endocrowns allow minimal tooth reduction and thus strengthen the teeth, by preserving sound dental tissues and root canal structures ${ }^{(4)}$.

Using endocrowns for restoration of premolars might be questionable due to the small dimensions of their pulp chambers and subsequently small surface area available for macro- and micromechanical bonding ${ }^{(8,23)}$. It has been reported that a minimum of $3 \mathrm{~mm}$ depth inside the pulp chamber are recommended to provide both macromechanical and micromechanical retention for endocrown preparations ${ }^{(24)}$. In this study, endocrowns were prepared with $4 \mathrm{~mm}$ depth inside the pulp chamber.

In the current study, composite endocrowns were fabricated using direct posterior resin composite with high filler loading (78wt $\%)$ and were subjected to additional polymerization in specialized oven after light curing. It was reported that direct posterior resin composites could be used for fabrication of indirect restorations with additional curing. Additional curing and high filler loading resulted in improved flexural strength to be $120-160 \mathrm{MPa}$ and elastic modulus to be 8.5-12 $\mathrm{GPa}^{(14)}$ which is considered matching to that of dentin ${ }^{(25)}$. In addition, direct resin composites are usually available in dental clinics for daily dental practice.

The results of the current study revealed that resin composite groups (group I, II and III) showed the highest mean fracture resistance values with no significant difference in comparison to the control group however, ceramic endocrowns revealed the lowest mean value. This could be attributed to the higher resilience and lower elastic modulus of resin composites compared to ceramics ${ }^{(26)}$. Thus, during loading resin composite is capable of more elastic deformation and stress absorption. In contrary, ceramics are rigid materials with high elastic modulus and less susceptibility to deformation which show brittleness and crack formation under stress ${ }^{(27)}$.

This was in agreement with previous researches ${ }^{(11,28,29)}$ which found that resin composite materials recorded higher fracture resistance compared to ceramic materials in restoration of endodontically treated maxillary premolars. Pedrollo Lise et al, $2017^{(30)}$, evaluated load to failure of lithium disilicate glass ceramic endocrowns versus resin composite endocrowns prepared for premolars and concluded that the use of composite materials with low elastic modulus is recommended in case of shallow endocrown preparations with small surface area available for adhesion.

Use of resin adhesive as a modeler liquid in fabrication of resin composite endocrowns revealed no significant difference in fracture resistance compared to sound premolars. The use of resin adhesives as modeler liquid might improve cohesiveness of resin composite which might be attributed to the lower possibility of presence of voids or defects within the bulk of the material making the restoration more densely packed and less susceptible to hydrolytic degradation and crack propagation ${ }^{(16)}$.

In the current study, the resin adhesive used in modeling of resin composite (Optibond All in one) contains $7 \%$ nanofillers. The use of adhesives with small percentage of fillers as a modeler liquid with highly filled resin composites might be the reason for their higher ability to resist fractures and cracking under load ${ }^{(10)}$. Kikuti et al, $2012^{(31)}$ found that the fracture resistance of teeth increased upon use of nanofilled adhesive with resin composite restorations and attributed this result to the creation of thicker adhesive layer which distribute stresses evenly with stress absorbing capacity. 
In the current study, resin composite modeled with flowable composite revealed a comparable fracture resistance to the control group. Low elastic modulus and high wettability of flowable composites relative to conventional composites supports the elastic wall concept ${ }^{(17,32)}$. This type of intermediate layer might absorb not only polymerization shrinkage stresses of resin composite but also stresses developed during functional loading of the restored teeth ${ }^{(32)}$. Almuhaiza \& Magdy, $2018^{(33)}$ reported improved fracture resistance of maxillary premolars restored with nanohybrid composite used with flowable bulk fill composite liner. Mosallam and Haridy, $2019^{(34)}$ found that the use of flowable composite as a base under ceramic endocrowns in restoration of endodontically treated maxillary premolars significantly improved fracture strength.

Use of resin composite modeled with flowable composite recorded higher mean fracture resistance than that modeled with resin adhesive with no significant difference between them. This might be due to the greater thickness of flowable composite in relation to the adhesive layer as the efficiency of absorbing stresses depends on the thickness of the intermediate layer ${ }^{(32)}$.

Regarding failure mode, different modes of failure were reported in the current study depending on the restorative approach used. Resin composite endocrowns prepared with different restorative approaches showed better performance than ceramic ones. Resin composite groups (group I, II and III) recoded mainly type II and type III fractures which are considered reparable ones. However, $70 \%$ of IPS lithium disilicate ceramic endocrowns recorded irreparable fractures involving teeth roots below level of bone crest (Type IV). This may be due to the difference in the modulus of elasticity of both materials as the modulus of elasticity of composite materials is compatible to that of dentin with tendency to bend under load with stress-absorbing properties.
On the contrary, lithium disilicate ceramics are rigid materials with high stiffness lacking the tendency to bend under stress with resultant stress concentration in the residual tooth structure and catastrophic types of failures ${ }^{(29,35)}$. Ramirez-Sebastia et al, $2013^{(36)}$ reported the presence of dentin cracks in specimens restored with ceramic crowns compared to that observed with resin composite crowns.

This finding was in accordance with previous studies $(4,10,29,35)$ which reported that failure patterns recorded by composite endocrowns were more favorable than those recorded by lithium disilicate ceramics which involved roots resulting in unrestorable teeth. Zhu et al, $2017^{(37)}$ recorded poor survival rates in terms of tooth preservation in association with ceramics compared to resin composite in restoration of maxillary premolars. They reported that increasing the elastic modulus of the material may be beneficial to bond durability between the endocrown and the tooth but on the other hand, it transfers stresses to residual tooth structure with increased irreparable failures ${ }^{(2)}$.

\section{CONCLUSION}

Based on this in-vitro study, it could be concluded that use of resin composite endocrowns is better choice compared to ceramic ones in restoration of endodontically treated premolars. Modeling of resin composite using flowable composite and resin adhesive is considered a promising approach in restoration of endodontically treated premolars with more favorable fracture behavior than ceramic materials.

\section{Financial support and sponsorship}

No financial support or sponsponsorship was received.

\section{Conflicts of interest}

There are no conflicts of interest. 


\section{REFERENCES}

1. Sun J, Ruan W, He J, Lin X, Ci B, Yin S et al. Clinical efficacy of different marginal forms of endocrowns: study protocol for a randomized controlled trial. Trials 2019; 20:454.

2. Vijayakumar JB, Varadan P, Balaji L, Rajan M, Kalaiselvam $R$, Saeralaathan $S$, et al. Fracture resistance of resin based and lithium disilicate endocrowns. Which is better? - A systematic review of in-vitro studies. Biomater Invest Dent 2021; 8:1041-111

3. Rocca GT and Krejci I. Crown and post-free adhesive restorations for endodontically treated posterior teeth: from direct composite to endocrowns. Eur J Esthet Dent 2013; 8(2): 156-179

4. El-Refaay AY, Hassan MR and Mohammed RM. Assessment of fracture resistance of endodontically treated premolars restored with endocrowns constructed of two different materials. Egy Dent J Research 2020;4: 533-542.

5. Mohammadi N, Kahnamoii MA, Yeganeh PK and Navimipour EJ. Effect of fiber post and cusp coverage on fracture resistance of endodontically treated maxillary premolars directly restored with composite resin. J Endod 2009; 35: 1428-1432.

6. Bindl A and Mörmann WH. Clinical evaluation of adhesive placed cerec endocrowns after 2 years preliminary results. Adhes Dent 1999; 1: 255-265.

7. Ghajghouj $\mathrm{O}$ and Tasar-Faruk S. Evaluation of fracture resistance and microleakage of endocrowns with different intracoronal depths and restorative materials luted with various resin cements. Materials 2019; 12: 2528.

8. Bindl A, Richter B and Mörmann WH. Survival of ceramic computer aided design / manufacturing crowns bonded to preparation with reduced macroretention geometry. Int $\mathrm{J}$ Prosthodont 2005; 18: 219-224.

9. Otto T and Mörmann WH. Clinical performance of chairside CAD/CAM feldspathic ceramic posterior shoulder crowns and endocrowns up to 12 years. Int J Comput Dent 2015; 18: 147-161.

10. Sedraz-Porto JA, Münchow EA, Valente LL, Cenci MS and Pereira-Cenci T. New material perspective for endocrown restorations: effects on mechanical performance and fracture behavior. Braz Oral Res 2019; 33: e012.

11. Soares PV, Santos-Filho PCF, Martins LRM and Soares CJ. Influence of restorative technique on the biomechanical behavior of endodontically treated maxillary premo- lars. Part I: fracture resistance and fracture mode. J Prosthet Dent 2008; 99: 30-37.

12. Thordrup M, Isidor F and Hörsted-Bindslev P. A prospective clinical study of indirect and direct composite and ceramic inlays: ten-year results. Quintessence Int 2006; 37(2): 139-144.

13. Leinfelder KF. Indirect posterior composite resins. Compend Contin Educ Dent 2005; 26(7): 495-503.

14. Nandini S. Indirect resin composite. J Conserv Dent 2010; 13(4): 184-194.

15. Sedrez-Porto JA, Münchow EA, Brondani LP, Cenci MS and Pereira-Cenci T. Effects of modeling liquid/resin and polishing on the color change of resin composite. Braz Oral Res 2016; 30(1): e88.

16. Münchow EA, Sedrez-Porto JA, Piva E, Pereira-Cenci T and Cenci MS. Use of dental adhesives as modeler liquid of resin composites. Dent Mater 2016; 32(4): 570-577.

17. Olliveira LC, Duarte S Jr, Araujo CA and Abrahão A. Effect of low-elastic modulus liner and base as stress-absorbing layer in composite resin restorations. Dent Mater 2010; 26: $159-169$.

18. Guray BE, Yaman BC, Gumustas B and Tiryaki M. The effects of glass ionomer and flowable composite liners on the fracture resistance of open-sandwich class II restorations. Dent Mater J 2013; 32(6): 877-882.

19. Schwartz RS and Robbins JW. Post placement and restoration of endodontically treated teeth: a literature review. J Endod 2004; 30: 289-301.

20. Belleflamme MM, Geerts SO, Louwette MM, Grenade $\mathrm{CF}$, Vanheusden AJ and Mainjot AK. No post-no core approach to restore severely damaged posterior teeth: An up to 10 -year retrospective study of documented endocrown cases. J Dent 2017;63:1-7.

21. Hayashi M, Takahashi Y, Imazato S and Ebisu S. Fracture resistance of pulpless teeth restored with post-cores and crowns. Dent Mater 2006; 22:477-485.

22. Biacchi GR, Mello B and Basting RT. The endocrown: an alternative approach for restoring extensively damaged molars. J Esthet Restor Dent 2013; 25: 383-390.

23. El Elagra M. Endocrown preparation: review. Int J Appl Dent Sci 2019; 5: 297-301.

24. Thomas RM, Kelly A, Tagiyeva $\mathrm{N}$ and Kanagasinga S. Comparing Endocrown restorations on permanent molars 
and premolars: a systemic review and meta-analysis. British Dent J 2020; Online publication.

25. De Andrade GS, Tribst JP, Dal Piva AO, Bottino MA, Borges ALS, Valandro LF, et al. Study on stress distribution to cement layer and root dentin for post and cores made of CAD/CAM materials with different elasticity modulus in the absence of ferrule. J Clin Exp Dent. 2019;11(1):e1-e8.

26. Tzimas K, Tsiafitsa M, Gerasimou P and Tsitrou E. Endocrown restorations for extensively damaged posterior teeth: clinical performance of three cases. Restor Dent Endod. 2018;43(4):e38.

27. Venturini AB, Prochnow C, Pereira GKR, Segala RD, Kleverlaan CJ and Valandro LF. Fatigue performance of adhesively cemented glass-, hybrid- and resinceramic materials for CAD/CAM monolithic restorations. Dent Mater 2019; 35: 534-542.

28. Magne P and Knezevic A. Simulated fatigue resistance of composite resin versus porcelain $\mathrm{CAD} / \mathrm{CAM}$ overlay restorations on endodontically treated molars. Quintessence Int 2009; 40: 125-133.

29. El-Damanhoury HM, Haj-Ali RN and Platt JA. Fracture resistance and microleakage of endocrowns utilizing three CAD-CAM blocks. Oper Dent 2015; 40: 201-210.

30. Pedrollo Lise D, Van Ende A, De Munck J, Suzuki TYU, Vieira LCC and Van Merrkbeek B. Biomechanical behavior of endodontically treated premolars using different preparation designs and CAD/CAM materials. J Dent 2017; 59: 54-61.
31. Kikuti WY, Chaves FO, Di Hipolito V, Rodrigues FP and D'Alpino PHP: Fracture resistance of teeth restored with different resin-based restorative systems. Braz Oral Res 2012; 26: 275-281.

32. Castañeda-Espinosa JC, Pereira RA, Cavalcanti AP and Mondelli RF. Transmission of composite polymerization contraction force through a flowable composite and a resin-modified glass ionomer cement. J Appl Oral Sci 2007; 15: 495-500.

33. Almuhaiza MS and Magdy NM. Cuspal deflection and fracture resistance in maxillary premolar teeth restored with bulk-fill flowable resin-based composite materials. Int J Health Sci Res 2018; 8(3): 105-112.

34. Mosallam RS and Haridy MF. Fracture strength of endodontically treated teeth restored with endocrown restorations with/without resin composite base materials - an in vitro study. Egy Dent J 2019; 65: 2837-2848.

35. Altier M, Erol F, Yıldırım G and Dalkilic EE. Fracture resistance and failure modes of lithium disilicate or composite endocrowns. Niger J Clin Pract 2018; 21:821-826.

36. Ramǐrez-Sebastia A, Bortolotto T, Roig M and Krejci I. Composite versus ceramic computer aided design / computer assissted manufacturing crowns in endodontically treated teeth analysis of marginal adaptation. Oper Dent 2013; 38(6): 663-673.

37. Zhu J, Rong Q, Wang X and Gao X. Influence of remaining tooth structure and restorative material type on stress distribution in endodontically treated maxillary premolars: a finite element analysis. J Prosthet Dent 2017; 117: 646-655. 